\title{
Incidence of sternal wound infection after tracheostomy in patients undergoing cardiac surgery: A systematic review and meta-analysis
}

\author{
Hadi Toeg, MD, MSc, MPH, ${ }^{\mathrm{a}}$ Daniel French, MD, MSc, ${ }^{\mathrm{b}}$ Sebastien Gilbert, MD, ${ }^{\mathrm{b}}$ and \\ Fraser Rubens, MD, MSc ${ }^{\mathrm{a}}$
}

\begin{abstract}
Purpose: This systematic review and meta-analysis was performed to determine whether timing or type of tracheostomy was associated with superficial or deep sternal wound infections after cardiac surgery.
\end{abstract}

Methods: All studies reporting the incidence of sternal wound infection after tracheostomy in patients undergoing cardiac surgery were collected and analyzed. Subgroup analyses determined a priori included timing of tracheostomy and type of procedure (open vs percutaneous). All analyses used the random effects model. A meta-regression analysis was performed on the proportion of sternal wound infection and number of days between tracheostomy and initial cardiac surgery.

Results: A total of 13 studies met inclusion criteria. The incidence of sternal wound infection across all studies reported was 7\% (95\% confidence interval [CI], 4-10). The percutaneous tracheostomy group had a sternal wound infection proportion of $3 \%(95 \% \mathrm{CI}, 1-8)$, and the open tracheostomy group had a sternal wound infection proportion of $9 \%(95 \% \mathrm{CI}, 5-14)$. The incidence of sternal wound infection with early (<14 days) $(7 \%$; 95\% CI, 3-11) versus late ( $\geq 14$ days) $(7 \% ; 95 \%$ CI, 4-10) tracheostomy was similar. Meta-regression demonstrated no significant relationship between incidence of sternal wound infection and number of days between tracheostomy and initial cardiac surgery $\left(\mathrm{R}^{2}=6.13 \%, P=.72\right)$. Reported secondary outcomes included 30-day and 1-year mortality, which were high at 23\% (95\% CI, 19-28) and 63\% (95\% CI, 43-80), respectively.

Conclusions: The incidence of sternal wound infection after tracheostomy in patients undergoing cardiac surgery remains high at 7\% (95\% CI, 4-10). Open or percutaneous tracheostomy after cardiac surgery is a feasible option because the incidence of sternal wound infection and short-term mortality are comparable. Moreover, the timing of tracheostomy (early or late) had comparable rates of sternal wound infection and short-term mortality. ( $\mathrm{J}$ Thorac Cardiovasc Surg 2017;153:1394-400)

Respiratory complications after cardiac surgery resulting in prolonged ventilation are common, particularly in high-risk subgroups. ${ }^{1}$ Tracheostomy can be performed in

\footnotetext{
From the ${ }^{a}$ Division of Cardiac Surgery, University of Ottawa Heart Institute; ${ }^{b}$ Division of Thoracic Surgery, University of Ottawa, Ottawa, Ontario, Canada.

Received for publication Feb 19, 2016; revisions received Oct 27, 2016; accepted for publication Nov 4, 2016; available ahead of print Dec 10, 2016.

Address for reprints: Hadi Toeg, MD, MSc, MPH, H3405-40 Ruskin St, Ottawa,

Ontario, Canada (E-mail: htoeg@ottawaheart.ca).

$0022-5223 / \$ 36.00$

Copyright (c) 2016 by The American Association for Thoracic Surgery

http://dx.doi.org/10.1016/j.jtcvs.2016.11.040
}

these patients to improve patient comfort and hasten ventilator weaning. 2,3 Although respiratory insufficiency or prolonged intubation dominate as the main reasons for tracheostomy, heart failure and neurologic dysfunction are additional indications. ${ }^{4}$

Scanning this QR code will take you to supplemental figures and tables for this article. 


\section{Abbreviations and Acronyms \\ $\mathrm{CI}=$ confidence interval \\ $\mathrm{POD}=$ postoperative day \\ $\mathrm{SWI}=$ sternal wound infection}

Tracheostomy can be performed via the traditional open method or percutaneous method. ${ }^{5,6}$ This procedure has been implicated as a significant risk factor in sternal wound infections (SWIs) or mediastinitis, ${ }^{7,8}$ although other groups have not confirmed this correlation. ${ }^{9,10}$ Procedure-related factors that have been proposed as potential contributors to SWI include the timing and type of tracheostomy. ${ }^{11,12}$ In the cardiac surgical population, the incidence of SWI has not been studied as a primary outcome except in 1 small retrospective study. ${ }^{11}$

Thus, the objective of this systematic review and meta-analysis was to report the incidence of SWI after tracheostomy in patients undergoing cardiac surgery and to determine whether the timing of tracheostomy (early vs late) or type of surgical technique (percutaneous vs open) resulted in a lower incidence of SWI.

\section{MATERIALS AND METHODS Eligibility Criteria}

Randomized controlled trials, cohort studies, and observational studies published in English between November 15, 1985, and December 15, 2015, dealing with patients who underwent tracheostomy after any form of cardiac surgery were considered. Studies were included if they reported the primary outcome of interest (incidence of SWI). Secondary outcomes of interest included 30-day and 1-year mortality. Studies that included patients who had tracheostomy before cardiac surgery or included patients who had SWI before tracheostomy were excluded. Studies with sample sizes less than 50 were excluded to reduce the small-study effect bias. ${ }^{13}$ Although this systematic search included a timeframe between 1985 and 2015, all studies included in the final analysis were published after the year 2000 .

\section{Information Source, Search Strategy, and Data Extraction}

The search strategy (Table E1) involved a detailed search of PubMED/MEDLINE, Embase, Cochrane Library, Clinical Trials Registry, relevant bibliographies, and Google Scholar. The methodology in this systematic review and meta-analysis conforms to PRISMA guidelines ${ }^{14}$ (Table E2, PRISMA checklist). There were a total of 562 articles identified on the initial search, which were then reviewed by 2 authors (HT and DF). After excluding articles on the basis of abstract information $(\mathrm{n}=332)$ and duplicity $(\mathrm{n}=198), 32$ articles remained for full article review. Detailed reasons for exclusion of 19 articles are shown in Table E3. A total of 13 articles were included for the analysis (Figure E1), ${ }^{1,4,7-12,15-19}$ All 13 studies underwent primary data extraction by 2 authors (HT and DF). Any discrepancy between the data extracted from individual studies was resolved by the involvement of a third author. Qualitative assessment of each study was performed using the National Heart, Lung, and Blood Institute Quality of Assessment Tool for Observational Cohort or Controlled Intervention Studies (Table E4). ${ }^{20}$

\section{Data Items and Outcome Measures}

The primary metameter of interest in this study was the incidence of SWI, which includes a composite outcome of superficial/deep SWI and mediastinitis incidence (based on the Society of Thoracic Surgeons definition). ${ }^{21}$ Secondary outcomes of interest included 30-day and 1-year mortality. Prespecified variables for subgroup analyses were extracted at the time of study review and placed into a standardized data-extraction form. These variables included type of tracheostomy (open vs percutaneous) and median postoperative days (PODs) between initial cardiac operation and tracheostomy. The latter variable was dichotomized to early $(\mathrm{POD}<14)$ versus late $(\mathrm{POD} \geq 14)$ tracheostomy for subgroup analysis.

\section{Statistical Methods}

All analyses used the random effects model, and measures of heterogeneity were assessed using the $\mathrm{Q}$ statistic and $\mathrm{I}^{2}$. Subgroup random-effects meta-analysis models on predetermined variables were performed for type of tracheostomy procedure (open vs percutaneous) and timing of tracheostomy procedure (early vs late). Finally, a meta-regression was performed between the incidence of SWI and the timing of tracheostomy (median POD) after cardiac surgery using an unrestricted maximum likelihood model. Statistical analysis and figure generation were performed using STATA Version 12 (StataCorp LP, College Station, Tex).

\section{RESULTS}

A total of 10,088 patients were included from 13 studies. The study characteristics including first author, year of publication, type of tracheostomy, mean age, sex, type of reported SWI, and other medical history are presented in Table 1. The overall incidence of SWI after tracheostomy in patients undergoing cardiac surgery was $7.0 \%(95 \%$ confidence interval [CI], 4-10) (Figure 1). Significant heterogeneity was observed on the basis of a high Q statistic $440.5(P<.0001)$ and $\mathrm{I}^{2}$ of $94.1 \%$ (Figure 1$)$. Subgroup analysis was performed by reporting the proportion of SWI based on type (Figure 2) and timing of tracheostomy (Figure 3). The proportion of SWI after percutaneous tracheostomy was 3\% (95\% CI, 1-8), whereas after open tracheostomy this was 9\% (95\% CI, 5-14) (Figure 2). Heterogeneity persisted in the open tracheostomy group $\left(\mathrm{I}^{2}=94.0 \%\right.$, Q-stat $\left.=151, P<.0001\right)$ but slightly decreased in the percutaneous group $\left(\mathrm{I}^{2}=84.8\right.$, Q-stat $=43, P<.001)$. The heterogeneity between subgroups was also different but not statistically significant (Q-stat $=2.2, P=.063$ ). In addition, the incidence of SWI was almost identical in both time eras (year <2007: 7\% [95\% CI, 3-12] vs years 2007-2014; 7\% [95\% CI, 2-13]).

The proportion of SWI was 7\% $(95 \%$ CI, 3-11) in the early tracheostomy group and $7 \%(95 \% \mathrm{CI}, 1-17)$ (Figure 3) in the late tracheostomy group. Heterogeneity persisted in both subgroups (early; $\mathrm{I}^{2}=91.1 \%$, late: $\left.\mathrm{I}^{2}=96.6\right)$. Heterogeneity between these subgroups was not significant $(P=.896)$. Meta-regression did not demonstrate a significant relationship between the timing of tracheostomy and the incidence of SWI, as depicted on the bubble plot $\left(\mathrm{R}^{2}=6.13 \%, P=.72\right.$ ) (Figure 4). Because most studies reported 30-day mortality and to a lesser extent 
TABLE 1. Summary of study-specific baseline characteristics

\begin{tabular}{lllclcccc}
\hline First author & Year & Country & Sample size (n) & Tracheostomy type & Age (y) & Sex (\% male) & $\begin{array}{c}\text { Median } \\
\text { POD (d) }\end{array}$ & Type of SWI reported \\
\hline Byhahn & 2000 & Germany & 144 & Percutaneous & - & 53 & 9 & Combination \\
Curtis & 2001 & USA & 81 & Open & 68 & 70 & 18.7 & Deep \\
Force & 2005 & USA & 291 & Open & 68 & 77 & 15.7 & Deep \\
Walts & 2006 & USA & 188 & Open & 69 & 55 & 14 & Superficial \\
Rahmanian & 2007 & USA & 108 & Open & 72 & 53 & 12.5 & Deep \\
Yavas $\dagger$ & 2008 & Turkey & 71 & Percutaneous & 62 & 72 & 12.2 & Deep \\
Yavas $\dagger$ & 2008 & Turkey & 134 & Open & 61 & 69 & 11.5 & Deep \\
Gaudino & 2009 & Italy & 57 & Open & 67 & 52 & 5.6 & Deep \\
Ballotta & 2011 & Italy & 131 & Percutaneous & - & 57 & 11.7 & Deep \\
Trouillet & 2011 & France & 109 & Percutaneous & 64 & 71 & 5 & Deep \\
Devarajan $\dagger$ & 2012 & USA & 112 & Open & 72 & 61 & 8 & Superficial \\
Devarajan $\dagger$ & 2012 & USA & 329 & Open & 72 & 62 & 18 & Superficial \\
Sun & 2013 & Canada & 411 & Open & 69 & 63 & 14 & Deep \\
Ben-Avi $\dagger$ & 2014 & Israel & 90 & Percutaneous & 69 & 53 & 7 & Deep \\
Ben-Avi $\dagger$ & 2014 & Israel & 109 & Percutaneous & 71 & 51 & 18 & Deep \\
Hosseinian & 2014 & USA & 7723 & Open & 70 & 56 & 13 & Deep \\
\hline
\end{tabular}

$P O D$, Postoperative day; $S W I$, sternal wound infection; $H T N$, hypertension; $C O P D$, chronic obstructive pulmonary disease; $D M$, diabetes; $L V E F$, left ventricular ejection fraction; $C A B G$, coronary artery bypass grafting. *Represents mean value. †Duplicates indicate subgroup comparisons within each study by early versus late groups (Trouillet 2011 ; Devarajan 2012; Ben-Avi 2014) or open versus percutaneous groups (Yavas 2008).

1-year mortality, secondary metameter of interest was 30-day and 1-year mortality. The overall 30-day mortality rate was $23 \%(95 \% \mathrm{CI}, 19-28)$. These values were comparable in the percutaneous group at $24 \%(95 \% \mathrm{CI}$, $10-41)$ and the open tracheostomy group at $23 \%(95 \%$ CI, 19-29) (Figure E2). Heterogeneity between these groups was not significant $(P=.992)$. Moreover, 30-day mortality was comparable when groups were dichotomized to early versus late tracheostomy with $22 \%$ (95\% CI, 16-30) and $25 \%$ (95\% CI, 17-35) (Figure E3). Heterogeneity between these groups also was nonsignificant $(P=.589)$.

The 1-year mortality rate was reported as $63 \%(95 \% \mathrm{CI}$, 43-80) and after subanalysis by type of tracheostomy performed, comparable mortality rates were observed with percutaneous at $67 \%(95 \% \mathrm{CI}, 51-82)$ and open tracheostomy at $56 \%(95 \% \mathrm{CI}, 16-92)$ (Figure E4). Because only 2 studies in the late tracheostomy group reported 1-year mortality, appropriate subanalysis based on timing of tracheostomy would not be constructive.

\section{DISCUSSION}

Tracheostomy is an invaluable procedure in the care of patients requiring prolonged ventilation after cardiac surgery; however, the impact of this intervention on SWI is not known. In this study, the incidence of SWI as a composite of superficial/deep SWI and mediastinitis after tracheostomy after cardiac surgery was determined to be $7 \%$ (95\% CI, 4-10). To determine whether the type or timing of tracheostomy was a potential source of heterogeneity, a priori subgroup analyses were performed. Although this study did not statistically compare the incidence of SWI by tracheostomy procedure, the percutaneous tracheostomy group had a $3 \%(95 \% \mathrm{CI}, 1-8)$ incidence of SWI, whereas the open tracheostomy group had a $9 \%(95 \%$ CI, 5-14) incidence of SWI. In addition to newer techniques, antibiotics, and prepping solutions in the percutaneous group, another potential reason for an observed lower incidence of SWI in the percutaneous group may be explained by the less-invasive nature of the operation. ${ }^{22}$ Heterogeneity also was borderline significant between the percutaneous and open tracheostomy groups $\left(\mathrm{I}^{2}=94.1 \% ; P=.063\right)$. This may be explained by the inherent selection bias: Patients receiving a percutaneous tracheostomy may be more hemodynamically stable or less obese. Compared with the open tracheostomy group, the percutaneous group had less within-group heterogeneity, further implying some degree of selection bias. Therefore, this could explain the observed lower proportion of SWI in the percutaneous group. Because the studies spanned a 15 -year period, we also performed a subanalysis dichotomized to early years of study $(<2007)$ to more recent years of study $(2007$ 2014). The incidence of SWI was almost identical in both eras $(<2007: 7 \%$ [95\% CI, 3-12] vs $2007-2014 ; 7 \%$ [95\% CI, 2-13]), implying that study era may not influence the incidence of SWI.

The timing of tracheostomy, dichotomized to early or late, demonstrated similar incidences of SWI. Heterogeneity in either subgroup persisted compared with the overall analysis. Last, a meta-regression analysis was performed and determined that no significant linear relationship existed between the incidence of SWI and median POD for tracheostomy. This finding is further corroborated by the exact same incidence of SWI after subgroup analysis in 
TABLE 1. Continued

\begin{tabular}{|c|c|c|c|c|c|c|c|c|c|}
\hline HTN $(\%) *$ & $\operatorname{COPD}(\%) *$ & DM $(\%)^{*}$ & $\begin{array}{c}\text { Renal } \\
\text { failure }(\%) *\end{array}$ & LVEF (\%)* & $\operatorname{Redo}(\%) *$ & CABG $(\%) *$ & $\begin{array}{c}\text { Valve } \\
\text { surgery }(\%)^{*}\end{array}$ & $\begin{array}{c}\text { 30-d } \\
\text { mortality }(\%)^{*} \\
\end{array}$ & $\begin{array}{c}1-y \\
\text { mortality }(\%) \\
\end{array}$ \\
\hline 50 & 11 & 26 & - & - & 29 & 65.3 & 9.7 & - & - \\
\hline - & 28.4 & 40 & - & - & 8.1 & - & - & 24.7 & - \\
\hline - & 20 & 36 & 19 & 45 & - & 65 & - & - & 22.7 \\
\hline - & 22 & 24 & 4 & - & 38 & 59 & 33 & 25 & - \\
\hline 78 & 18.5 & 32 & 10.2 & - & 25.9 & 20.4 & 31.5 & 11.1 & - \\
\hline - & 50.7 & 39 & 25.4 & - & 43.7 & - & - & - & 84.5 \\
\hline - & 49.3 & 46 & 32.1 & - & 47.8 & - & - & - & 81.3 \\
\hline 25.9 & 55.4 & 32 & - & - & 25.9 & 31.6 & 54.4 & 19.2 & 63.1 \\
\hline 8.2 & 15.3 & 16 & - & 45 & 11 & 32 & - & 49 & 71 \\
\hline - & 11 & 24 & 16 & - & - & 25 & - & 16 & 35.8 \\
\hline 75.4 & 24.4 & 39 & - & - & 40.5 & 70.7 & - & 22 & - \\
\hline 71.9 & 18.3 & 41 & - & - & 40.5 & 60.4 & - & 36.1 & - \\
\hline- & 19.5 & 34 & - & - & 16.8 & - & - & - & - \\
\hline 64 & 17 & 29 & 4 & 46 & 34 & 16 & 20 & 17.8 & 55.6 \\
\hline 59 & 15 & 45 & 6 & 45 & 29 & 26 & 24 & 15.6 & 74.3 \\
\hline - & 25 & - & 24.5 & - & - & 49.5 & - & 24.6 & - \\
\hline
\end{tabular}

early versus late tracheostomy groups. The incidence of SWI in tracheostomy cases after cardiac surgery is larger than the general cardiac surgical population, which has been reported to range from $0.7 \%$ to $3.2 \% .^{23-25}$ The increased incidence of SWI may be partially explained by several other risk factors present in postoperative

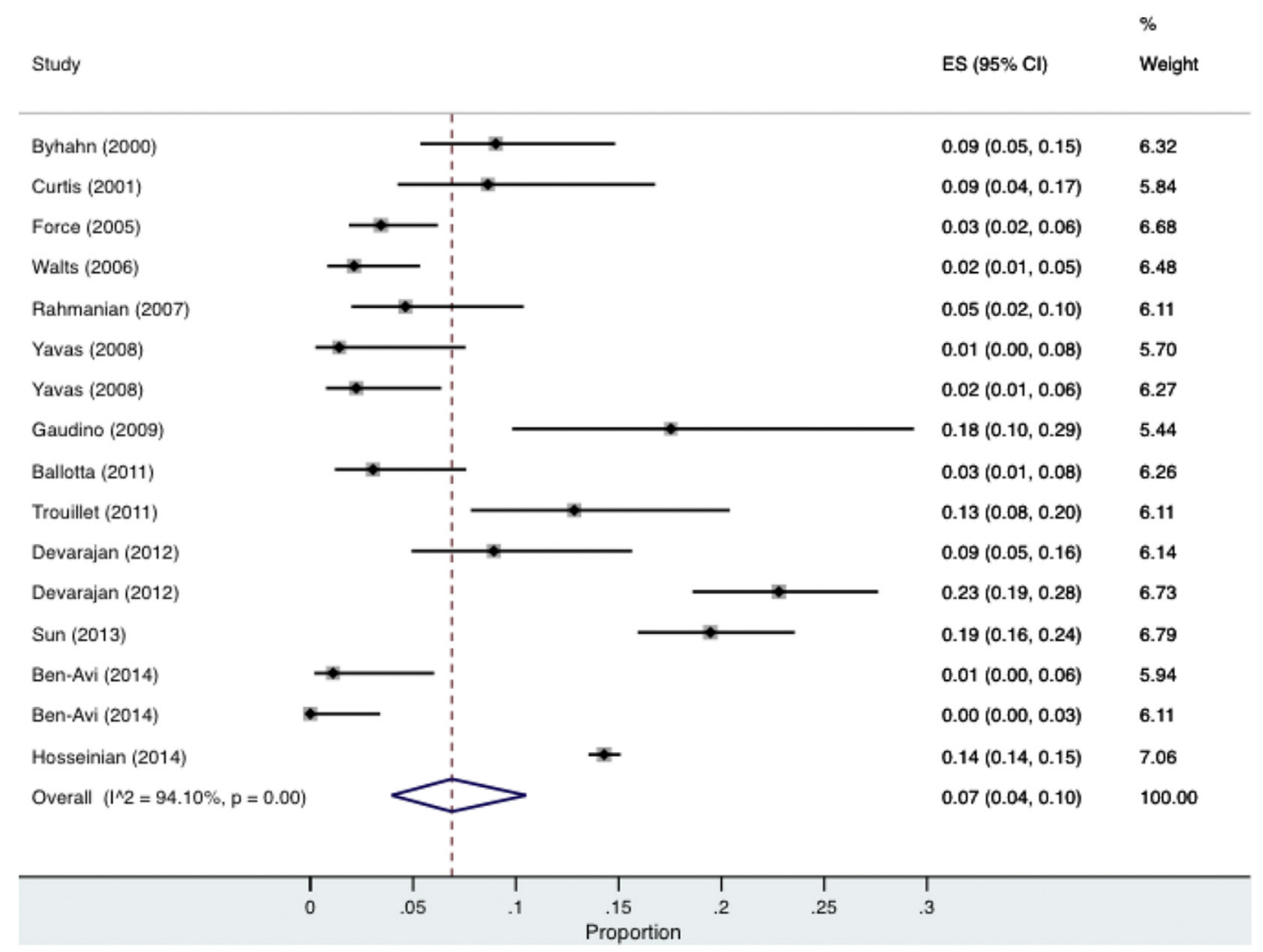

(Sternal Wound Infection)

FIGURE 1. Forest plot with proportion of SWI after tracheostomy across all studies. Duplicate studies represent early versus late groups of patients. $E S$, Effect size/incidence; $C I$, confidence interval. 


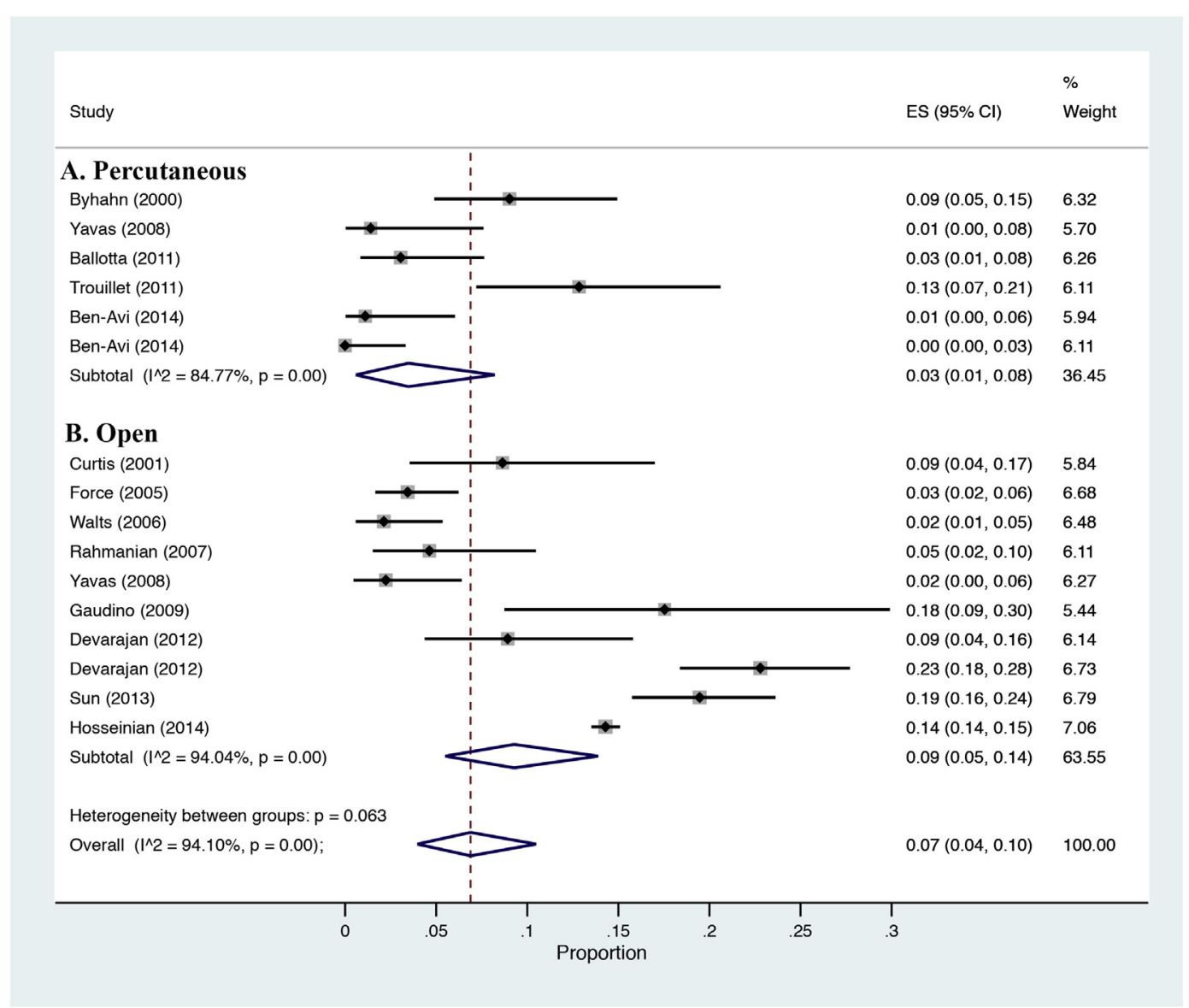

(Sternal Wound Infection)

FIGURE 2. Subgroup analysis of the proportion of SWI after percutaneous (A) or open (B) tracheostomy. ES, Effect size/incidence; $C I$, confidence interval.

tracheostomy cases. For example, in this meta-analysis of more than 10,000 patients, there was a high incidence of diabetic patients, elderly patients, patients with chronic obstructive lung disease, and patients undergoing reoperative surgery. ${ }^{10}$ This potentially supports the belief that tracheostomy may not be a risk factor for developing SWI but merely acts as an overall indicator of patient critical illness. Significant heterogeneity was observed in the meta-analysis for overall incidence of SWI with an $\mathrm{I}^{2}=94.1 \%$. This may be partially explained by the variability in reporting superficial or deep SWIs (several modifications for diagnostic criteria have been made over the last decade) and the lack of controlled study designs (11/13 studies were retrospective).

The secondary metameter of interest included 30-day and 1-year mortality, which were high at $23 \%$ (95\% CI, 19-28) and $63 \%(95 \%$ CI, 43-80), respectively. Furthermore, after stratifying by type of tracheostomy procedure, the 30-day and 1-year mortality rates were identical. This implies that percutaneous or open tracheostomy is a safe option for patients undergoing cardiac surgery with respiratory failure. Likewise, the timing of tracheostomy (early vs late) did not change the 30-day mortality, implicating that either timing option is feasible. Despite no major differences in mortality between type and timing of tracheostomy, the absolute 30-day and 1-year mortality rates were high at $23 \%$ and $63 \%$, respectively. These elevated mortality rates are likely a surrogate marker of significant disease burden and poor long-term outcomes as opposed to the tracheostomy procedure itself, a procedure typically with a low perioperative mortality $(<1 \%){ }^{26}$

\section{Study Limitations}

The large amount of heterogeneity is a limitation of the current study. Attempts to identify potential sources of heterogeneity with subgroup analyses failed to fully explain this finding. As discussed previously, major sources of heterogeneity may include the varying diagnostic criteria for SWI, a wide range of cardiac surgical procedures (multivalve, bypass, type of grafts including bilateral vs single internal thoracic artery), patient comorbidities, and 


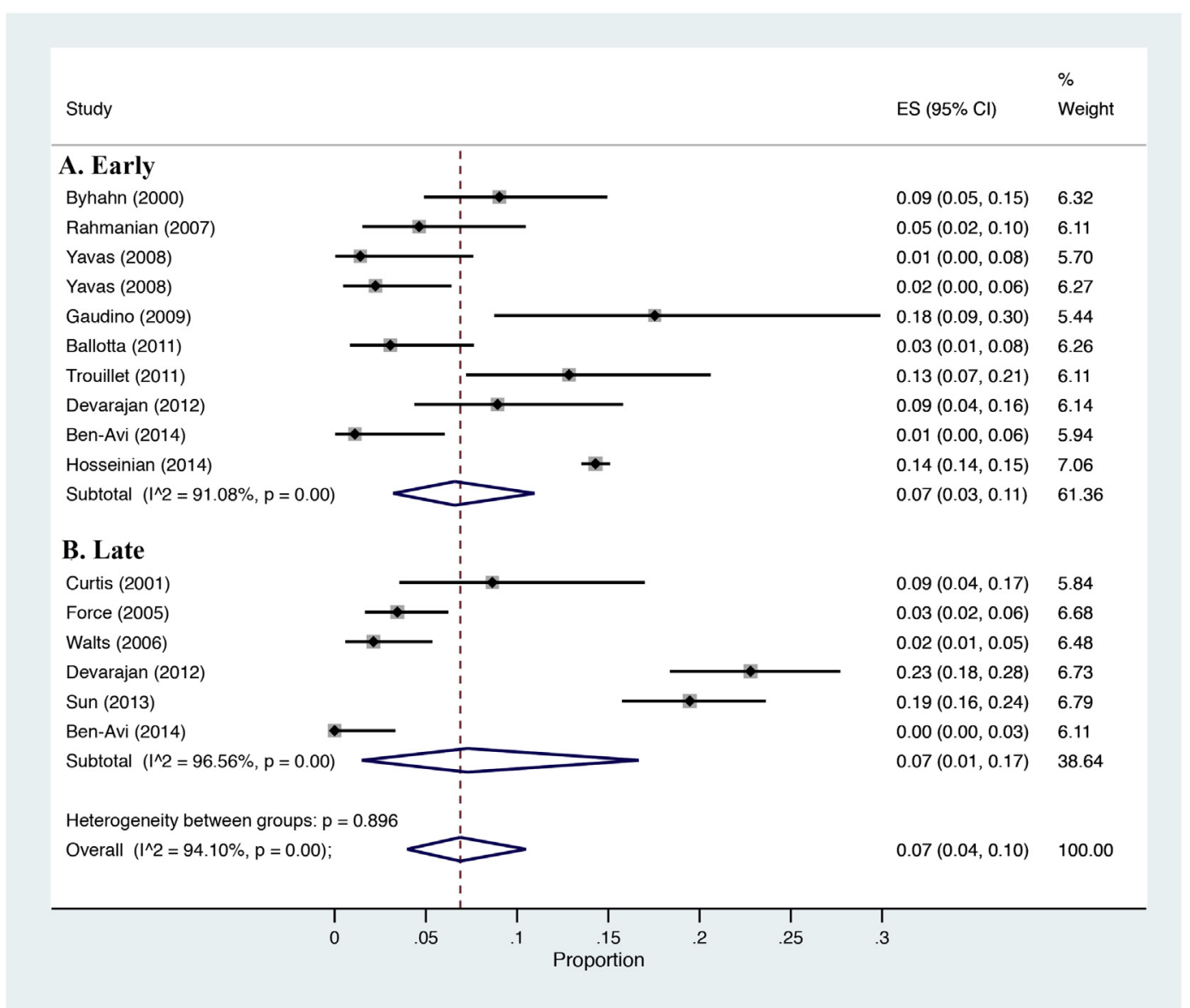

(Sternal Wound Infection)

FIGURE 3. Subgroup analysis of the proportion of SWI found in early (A) tracheostomy versus late (B) tracheostomy. ES, Effect size/incidence; $C I$, confidence interval.

small datasets, most of which are retrospective in nature. In addition to varying diagnostic criteria for SWI, some studies reported only superficial ${ }^{2,17}$ or a combination of superficial/deep $\operatorname{SWI}^{15}(\mathrm{n}=3)$, whereas the remaining

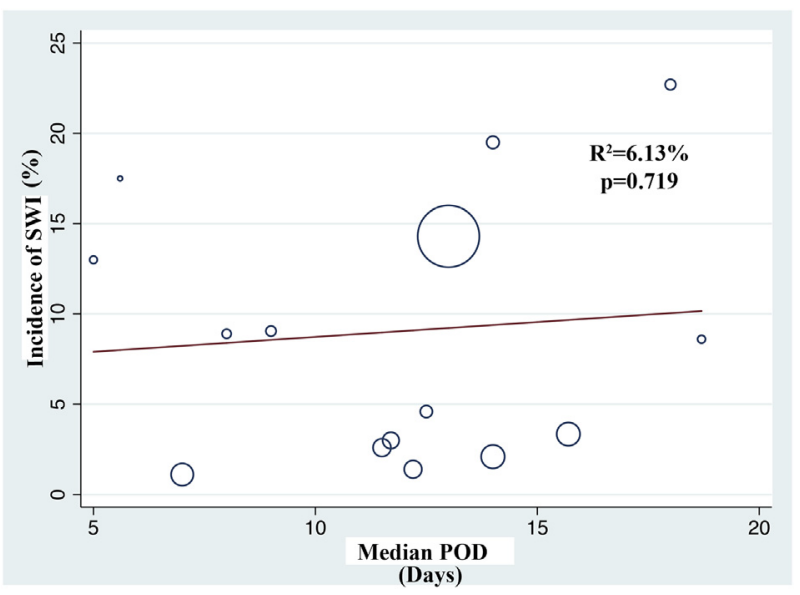

FIGURE 4. Meta-regression (bubble blot) comparing the incidence of SWI with the median POD from tracheostomy to initial cardiac surgery. $S W I$, Sternal wound infection; $P O D$, postoperative day. studies reported deep-seated SWI or mediastinitis (10/13). When the studies reporting superficial SWI were removed, the overall effect estimate and the degree of heterogeneity did not change. Although this meta-analysis collected only a handful of studies $(\mathrm{n}=13)$, publication bias seemed to be minimal according to the Egger's test $(P=.15)$; however, the Begg's test $(P=.053)$ used for assessment of publication bias demonstrates that there is likely some degree of publication bias due to the equivocal $P$ value. Despite these limitations, this is the only study that has systematically reported the incidence of SWI after tracheostomy in patients undergoing cardiac surgery and looked at whether the type or the timing of tracheostomy played a role in the development of SWI.

\section{CONCLUSIONS}

The incidence of SWI followed by tracheostomy in patients undergoing cardiac surgery remains high at $7 \%$. Open or percutaneous tracheostomy after cardiac surgery is a feasible option because SWI incidence and short-term mortality are comparable. Furthermore, although the timing 
of tracheostomy (early vs late) may improve patient comfort and weaning from ventilation as described previously, ${ }^{12}$ this meta-analysis demonstrated comparable proportions of SWI and short-term mortality. Further studies are needed to determine which strategy (open vs percutaneous; early vs late) generates faster patient recovery and lowers overall cost.

\section{Conflict of Interest Statement}

Authors have nothing to disclose with regard to commercial support.

\section{References}

1. Ben-Avi R, Ben-Nun A, Levin S, Simansky D, Zeitlin N, Sternik L, et al. Tracheostomy after cardiac surgery: timing of tracheostomy as a risk factor for mortality. J Cardiothorac Vasc Anesth. 2014;28:493-6.

2. Walts PA, Murthy SC, Arroliga AC, Yared JP, Rajeswaran J, Rice TW, et al. Tracheostomy after cardiovascular surgery: an assessment of long-term outcome. J Thorac Cardiovasc Surg. 2006;131:830-7.

3. Ranucci M, Castelvecchio S, Menicanti L, Frigiola A, Pelissero G. Risk of assessing mortality risk in elective cardiac operations: age, creatinine, ejection fraction, and the law of parsimony. Circulation. 2009;119:3053-61.

4. Ballotta A, Kandil H, Generali T, Menicanti L, Pelissero G, Ranucci M. Tracheostomy after cardiac operations: In-hospital and long-term survival. Ann Thorac Surg. 2011;92:528-34.

5. Bacchetta MD, Girardi LN, Southard EJ, Mack CA, Ko W, Tortolani AJ, et al. Comparison of open versus bedside percutaneous dilatational tracheostomy in the cardiothoracic surgical patient: outcomes and financial analysis. Ann Thorac Surg. 2005;79:1879-85

6. Freeman BD, Isabella K, Cobb JP, Boyle WA III, Schmieg RE Jr, Kolleff MH, et al. A prospective, randomized study comparing percutaneous with surgical tracheostomy in critically ill patients. Crit Care Med. 2001;29:926-30.

7. Force SD, Miller DL, Petersen R, Mansour KA, Craver J, Guyton RA, et al Incidence of deep sternal wound infections after tracheostomy in cardiac surgery patients. Ann Thorac Surg. 2005;80:618-22.

8. Sun L, Boodhwani M, Baer H, McDonald B. The association between tracheostomy and sternal wound infection in postoperative cardiac surgery patients. Can J Anaesth. 2013;60:684-91.

9. Gaudino M, Losasso G, Anselmi A, Zamparelli R, Schiavello R, Possati G. Is early tracheostomy a risk factor for mediastinitis after median sternotomy? J Card Surg. 2009;24:632-6.

10. Rahmanian PB, Adams DH, Castillo JG, Chikwe J, Filsoufi F. Tracheostomy is not a risk factor for deep sternal wound infection after cardiac surgery. Ann Thorac Surg. 2007;84:1984-91.

11. Yavas S, Yagar S, Mavioglu L, Cetin E, Iscan HZ, Ulus AT, et al. Tracheostomy: how and when should it be done in cardiovascular surgery ICU? J Card Surg. 2009;24:11-8.
12. Trouillet JL, Luyt CE, Guiguet M, Ouattara A, Vaissier E, Makri R, et al. Early percutaneous tracheotomy versus prolonged intubation of mechanically ventilated patients after cardiac surgery: a randomized trial. Ann Intern Med. 2011;154:373-83.

13. Sterne JA, Gavaghan D, Egger M. Publication and related bias in meta-analysis: power of statistical tests and prevalence in the literature. J Clin Epidemiol. 2000; 53:1119-29.

14. Moher D, Shamseer L, Clarke M, Ghersi D, Liberati A, Petticrew M, et al. Preferred reporting items for systematic review and meta-analysis protocols (PRISMA-P) 2015 statement. Syst Rev. 2015;4:1.

15. Byhahn C, Rinne T, Halbig S, Albert S, Wilke HJ, Lischke V, et al. Early percutaneous tracheostomy after median sternotomy. J Thorac Cardiovasc Surg. 2000;120:329-34.

16. Curtis JJ, Clark NC, McKenney CA, Walls JT, Schmaltz RA, Demmy TL, et al. Tracheostomy: a risk factor for mediastinitis after cardiac operation. Ann Thorac Surg. 2001;72:731-4.

17. Devarajan J, Vydyanathan A, Xu M, Murthy SM, McCurry KR, Sessler DI, et al. Early tracheostomy is associated with improved outcomes in patients who require prolonged mechanical ventilation after cardiac surgery. J Am Coll Surg. 2012;214:1008-16.e4.

18. Hosseinian L, Chiang Y, Itagaki S, Polanco A, Rhee A, Chikwe J. Earlier versus later tracheostomy in patients with respiratory failure after cardiac surgery in the United States. J Cardiothorac Vasc Anesth. 2014;28:488-92.

19. Wagner F, Nasseri R, Laucke U, Hetzer R. Percutaneous dilatational tracheostomy: results and long-term outcome of critically ill patients following cardiac surgery. Thorac Cardiovasc Surg. 1998;46:352-6.

20. Quality Assessment Tool for Observational Cohort and Cross-Sectional Studies. Bethesda, MD: National Institutes of Health, National Heart, Lung, and Blood Institute; 2014.

21. Salehi Omran A, Karimi A, Ahmadi SH, Davoodi S, Marzban M, Movahedi N, et al. Superficial and deep sternal wound infection after more than 9000 coronary artery bypass graft $(\mathrm{CABG})$ : incidence, risk factors and mortality. BMC Infect Dis. 2007;7:112.

22. Hsiao CY, Ou-Yang CP, Huang CH. Less invasive cardiac surgery via partial sternotomy. J Chin Med Assoc. 2012;75:630-4.

23. Kirmani BH, Mazhar K, Saleh HZ, Ward AN, Shaw M, Fabri BM, et al. External validity of the Society of Thoracic Surgeons risk stratification tool for deep sternal wound infection after cardiac surgery in a UK population. Interact Cardiovasc Thorac Surg. 2013;17:479-84.

24. Kubota H, Miyata H, Motomura N, Ono M, Takamoto S, Harii K, et al. Deep sternal wound infection after cardiac surgery. J Cardiothorac Surg. 2013; $8: 132$.

25. Lemaignen A, Birgand G, Ghodhbane W, Alkhoder S, Lolom I, Belorgey S, et al. Sternal wound infection after cardiac surgery: incidence and risk factors according to clinical presentation. Clin Microbiol Infect. 2015;21:674.e11-8

26. Engoren M, Arslanian-Engoren C, Fenn-Buderer N. Hospital and long-term outcome after tracheostomy for respiratory failure. Chest. 2004;125:220-7.

Key Words: cardiac surgery, sternal wound infection, tracheostomy 

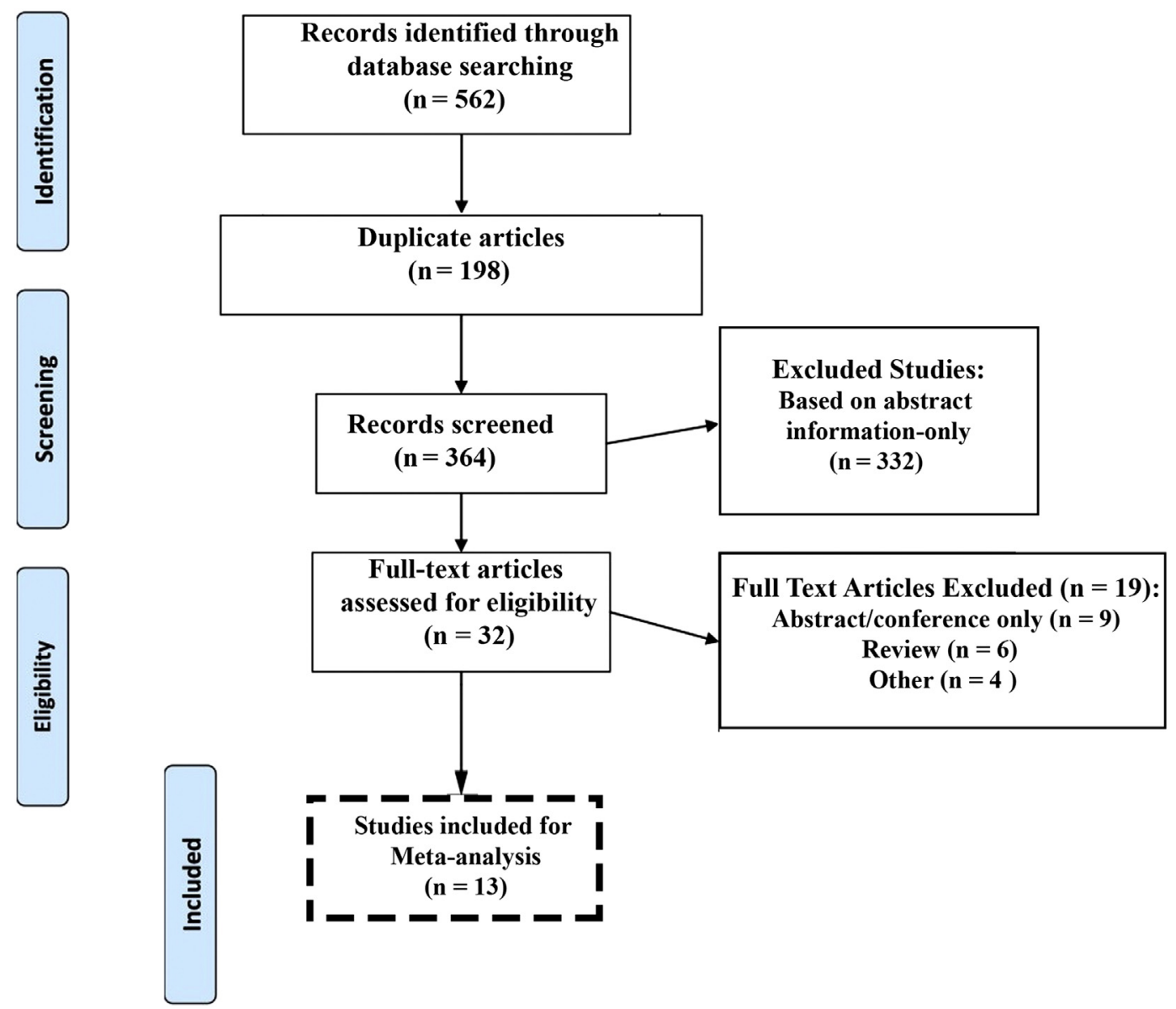

FIGURE E1. Flow diagram. 


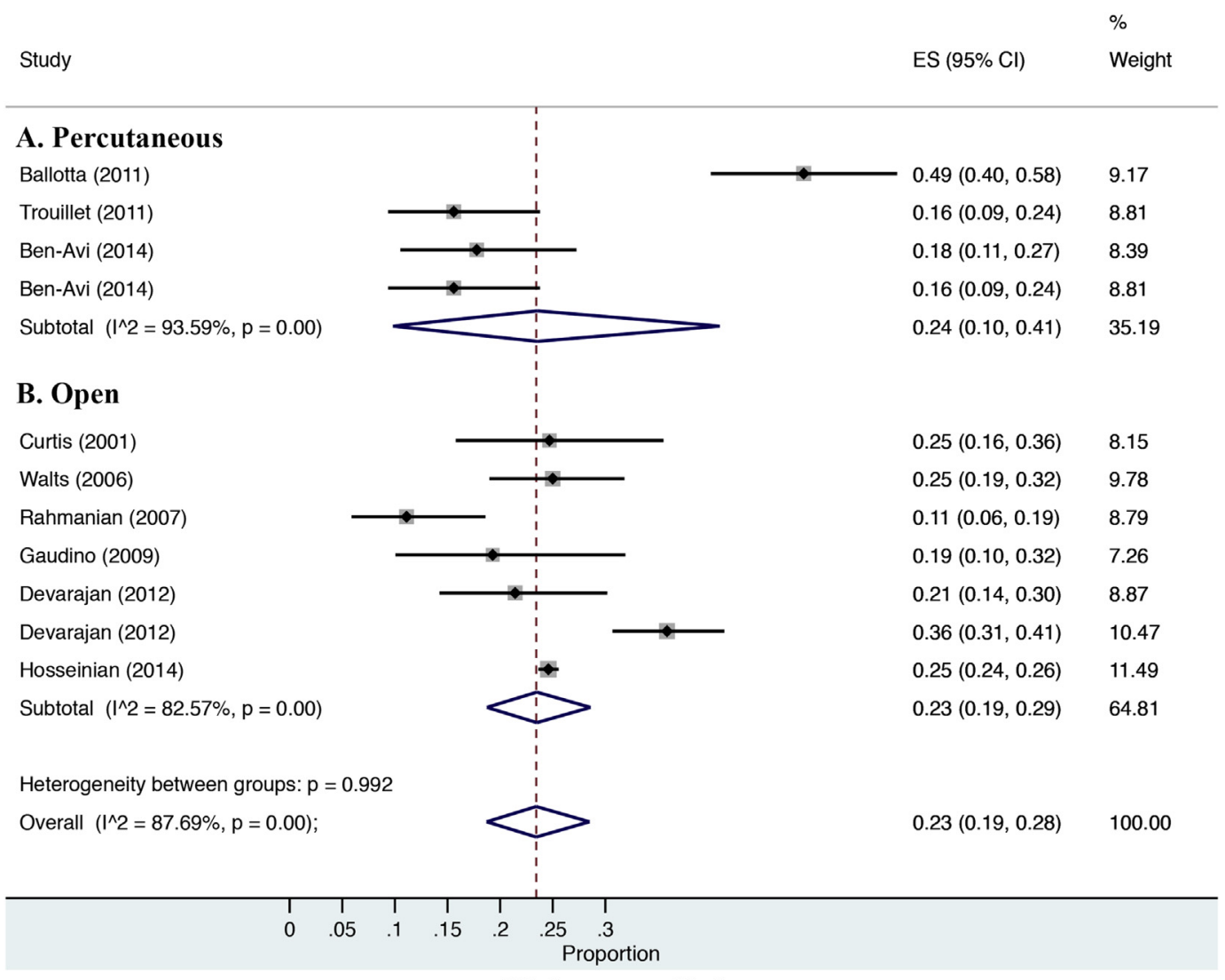

(30 day mortality)

FIGURE E2. Forest plot subgroup analysis of the 30-day mortality after percutaneous (A) or open (B) tracheostomy. ES, Effect size/incidence; CI, confidence interval. 


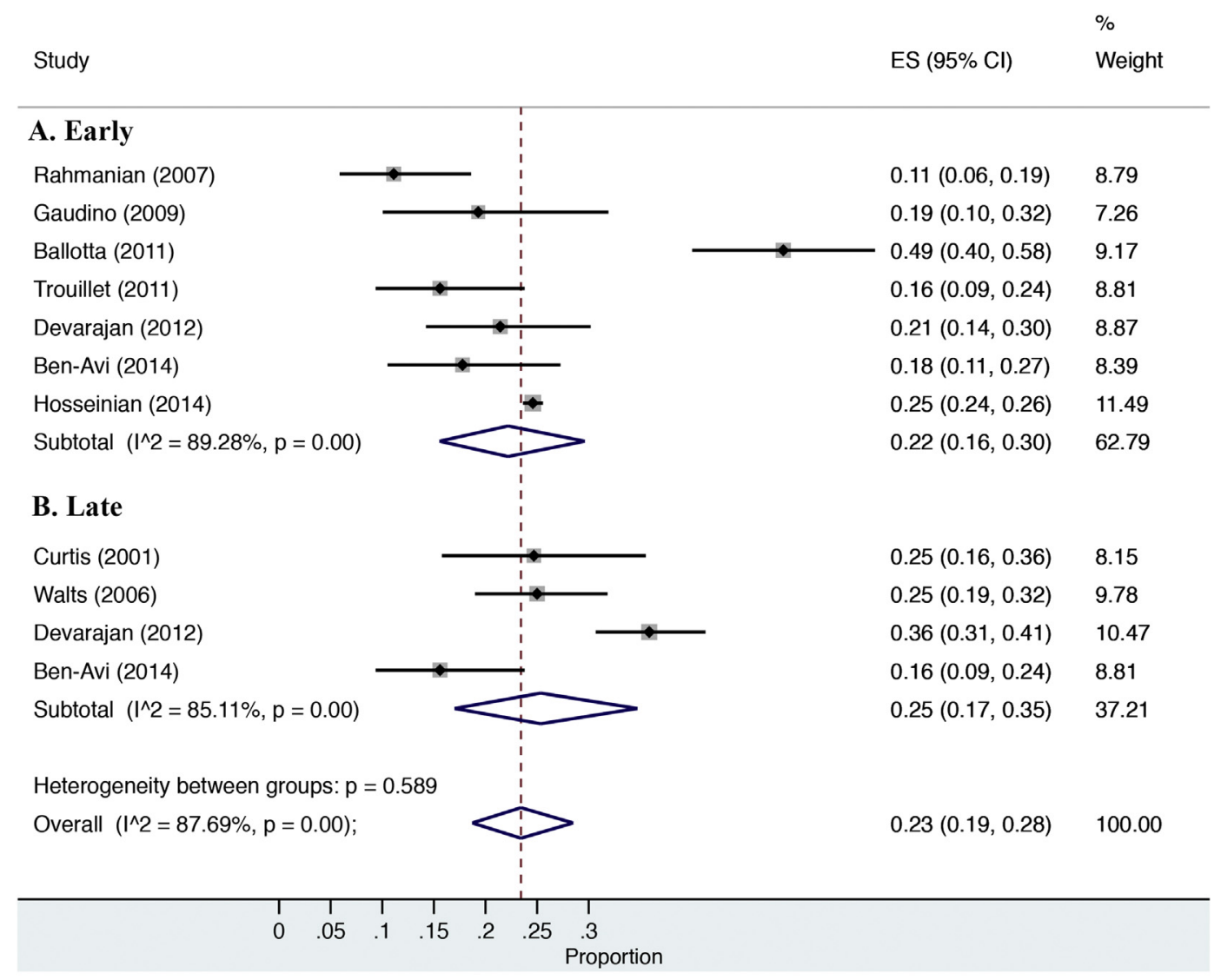

(30 day mortality)

FIGURE E3. Forest plot subgroup analysis of the 30-day mortality after early (A) or late (B) tracheostomy. ES, Effect size/incidence; CI, confidence interval. 


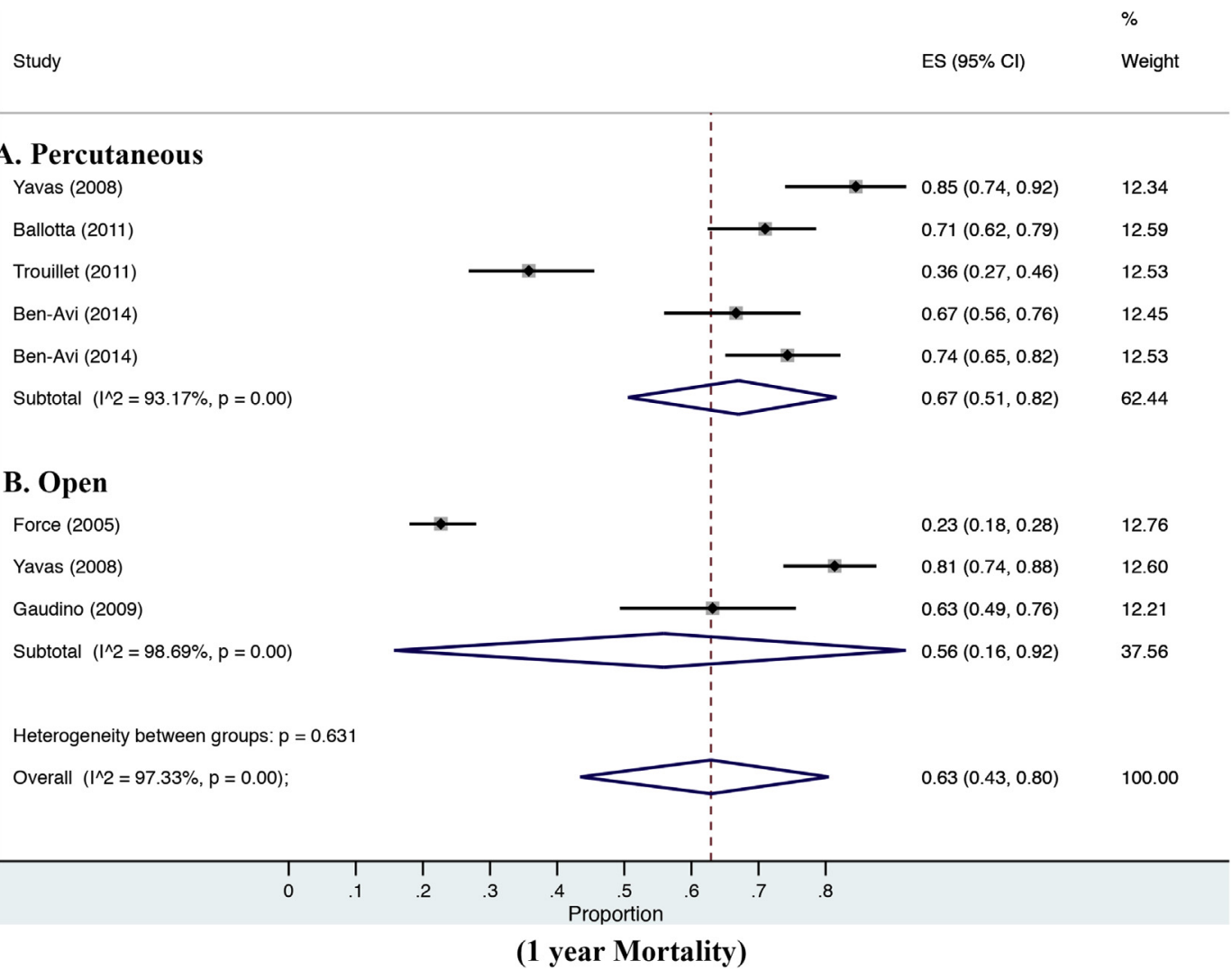

FIGURE E4. Forest plot subgroup analysis of the 1-year mortality after percutaneous (A) or open (B) tracheostomy. ES, Effect size/incidence; $C I$, confidence interval. 
TABLE E1. Search methodology

\begin{tabular}{|c|c|c|}
\hline Database & Specific search strategy & Keywords searched \\
\hline PubMed/MEDLINE & $\begin{aligned} 1 & =\text { thoracic surgery } / \\
2 & =\text { exp Cardiac Surgical Procedures/ } \\
3 & =\text { Cardiopulmonary Bypass/ } \\
4 & =((\text { cardiac or heart) adj2 }(\text { surg* or operation* or bypass or } \\
& \text { transplant } *)) . t w . \\
5 & =(\text { coronary artery adj2 (bypass or surg* or graft } *)) . t w . \\
6 & =\text { cabg.tw. } \\
7 & =((\text { cardiac or mitral) adj2 (annuloplasty or surg*)).tw. } \\
8 & =\text { or/ } 1-7 \\
9 & =\text { exp heart diseases/ } \\
10 & =\text { su.fs. } \\
11 & =9 \text { and } 10 \\
12 & =8 \text { or } 11 \\
13 & =\text { tracheostom*.hw,tw. } \\
14 & =12 \text { and } 13\end{aligned}$ & $\begin{array}{l}\text { Cardiac Surgery*, Thoracic Surgery*, } \\
\text { Tracheostomy* }\end{array}$ \\
\hline EMBASE & $\begin{array}{l}1=\text { thoracic surgery } / \\
2=\text { Cardiopulmonary Bypass } / \\
3=((\text { cardiac or heart) adj2 (surg* or operation* or bypass or } \\
\quad \text { transplant*)).tw. } \\
4=(\text { coronary artery adj2 (bypass or surg* or graft*)).tw. } \\
5=\text { cabg.tw. } \\
6=((\text { cardiac or mitral) adj2 (annuloplasty or surg*)).tw. } \\
7=\text { or/ } 1-6 \\
8=\text { tracheostom*.hw,tw. } \\
9=7 \text { and } 8\end{array}$ & $\begin{array}{l}\text { Cardiac Surgery*, Thoracic Surgery*, } \\
\text { Tracheostomy* }\end{array}$ \\
\hline Google Scholar & Not applicable & $\begin{array}{l}\text { Cardiac Surgery or Thoracic Surgery or } \\
\text { coronary artery bypass surgery, Tracheostomy* }\end{array}$ \\
\hline Clinical Trials Registry & Not applicable & Cardiac Surgery*, Thoracic Surgery*, Tracheostomy* \\
\hline Cochrane Library & Not applicable & Cardiac Surgery*, Thoracic Surgery*, Tracheostomy* \\
\hline
\end{tabular}


TABLE E2. PRISMA checklist

\begin{tabular}{|c|c|c|c|}
\hline Section/topic & No. & Checklist item & Reported on page no. \\
\hline \multicolumn{4}{|l|}{ Title } \\
\hline Title & 1 & Identify the report as a systematic review, meta-analysis, or both. & 1 \\
\hline \multicolumn{4}{|l|}{ Abstract } \\
\hline Structured summary & 2 & $\begin{array}{l}\text { Provide a structured summary including, as applicable, background; } \\
\text { objectives; data sources; study eligibility criteria, participants, and } \\
\text { interventions; study appraisal and synthesis methods; results; limitations; } \\
\text { conclusions and implications of key findings; systematic review } \\
\text { registration number. }\end{array}$ & 3 \\
\hline \multicolumn{4}{|l|}{ Introduction } \\
\hline Rationale & 3 & Describe the rationale for the review in the context of what is already known. & 5 \\
\hline Objectives & 4 & $\begin{array}{l}\text { Provide an explicit statement of questions being addressed with reference to } \\
\text { PICOS. }\end{array}$ & 5 \\
\hline \multicolumn{4}{|l|}{ Methods } \\
\hline Protocol and registration & 5 & $\begin{array}{l}\text { Indicate if a review protocol exists, if and where it can be accessed (eg, Web } \\
\text { address), and, if available, provide registration information including } \\
\text { registration number. }\end{array}$ & 6 \\
\hline Eligibility criteria & 6 & $\begin{array}{l}\text { Specify study characteristics (eg, PICOS, length of follow-up) and report } \\
\text { characteristics (eg, years considered, language, publication status) } \\
\text { used as criteria for eligibility, giving rationale. }\end{array}$ & 6 \\
\hline Information sources & 7 & $\begin{array}{l}\text { Describe all information sources (eg, databases with dates of coverage, } \\
\text { contact with study authors to identify additional studies) in the search } \\
\text { and date last searched. }\end{array}$ & 6 \\
\hline Search & 8 & $\begin{array}{l}\text { Present full electronic search strategy for at least } 1 \text { database, including any } \\
\text { limits used, such that it could be repeated. }\end{array}$ & 6 \\
\hline Study selection & 9 & $\begin{array}{l}\text { State the process for selecting studies (ie, screening, eligibility, included in } \\
\text { systematic review, and, if applicable, included in the meta-analysis). }\end{array}$ & 6 \\
\hline Data collection process & 10 & $\begin{array}{l}\text { Describe method of data extraction from reports (eg, piloted forms, } \\
\text { independently, in duplicate) and any processes for obtaining and } \\
\text { confirming data from investigators. }\end{array}$ & 6 \\
\hline Data items & 11 & $\begin{array}{l}\text { List and define all variables for which data were sought (eg, PICOS, funding } \\
\text { sources) and any assumptions and simplifications made. }\end{array}$ & 6 \\
\hline Risk of bias in individual studies & 12 & $\begin{array}{l}\text { Describe methods used for assessing risk of bias of individual studies } \\
\text { (including specification of whether this was done at the study or } \\
\text { outcome level), and how this information is to be used in any data } \\
\text { synthesis. }\end{array}$ & 6 \\
\hline Summary measures & 13 & State the principal summary measures (eg, risk ratio, difference in means). & $6-7$ \\
\hline Synthesis of results & 14 & $\begin{array}{l}\text { Describe the methods of handling data and combining results of studies, if } \\
\text { done, including measures of consistency }\left(\mathrm{eg}, \mathrm{I}^{2}\right) \text { for each meta- } \\
\text { analysis. }\end{array}$ & $6-7$ \\
\hline Risk of bias across studies & 15 & $\begin{array}{l}\text { Specify any assessment of risk of bias that may affect the cumulative } \\
\text { evidence (eg, publication bias, selective reporting within studies). }\end{array}$ & 12 \\
\hline Additional analyses & 16 & $\begin{array}{l}\text { Describe methods of additional analyses (eg, sensitivity or subgroup } \\
\text { analyses, meta-regression), if done, indicating which were prespecified. }\end{array}$ & $7-8$ \\
\hline
\end{tabular}

Results

Study selection

Give numbers of studies screened, assessed for eligibility, and included in the review, with reasons for exclusions at each stage, ideally with a flow diagram.

Study characteristics

For each study, present characteristics for which data were extracted (eg, study size, PICOS, follow-up period) and provide the citations.

Risk of bias within studies

Present data on risk of bias of each study and, if available, any outcome level assessment (see item 12).

Results of individual studies and CIs, ideally with a forest plot.

Figure E1, Table E4

Table E1

Table E3

Figure 1 
TABLE E2. Continued

\begin{tabular}{|c|c|c|c|}
\hline Section/topic & No. & Checklist item & Reported on page no. \\
\hline Synthesis of results & 21 & $\begin{array}{l}\text { Present results of each meta-analysis done, including CIs and measures of } \\
\text { consistency. }\end{array}$ & Figures 1-4 \\
\hline Risk of bias across studies & 22 & Present results of any assessment of risk of bias across studies (see Item 15). & 12 \\
\hline Additional analysis & 23 & $\begin{array}{l}\text { Give results of additional analyses, if done (eg, sensitivity or subgroup } \\
\text { analyses, meta-regression [see Item 16]). }\end{array}$ & Figure 4, Figures E2-E4 \\
\hline \multicolumn{4}{|l|}{ Discussion } \\
\hline Summary of evidence & 24 & $\begin{array}{l}\text { Summarize the main findings including the strength of evidence for each } \\
\text { main outcome; consider their relevance to key groups (eg, healthcare } \\
\text { providers, users, and policy makers). }\end{array}$ & 13 \\
\hline Limitations & 25 & $\begin{array}{l}\text { Discuss limitations at study and outcome level (eg, risk of bias), and at } \\
\text { review level (eg, incomplete retrieval of identified research, reporting } \\
\text { bias). }\end{array}$ & 12 \\
\hline Conclusions & 26 & $\begin{array}{l}\text { Provide a general interpretation of the results in the context of other } \\
\text { evidence, and implications for future research. }\end{array}$ & 13 \\
\hline \multicolumn{4}{|l|}{ Funding } \\
\hline Funding & 27 & $\begin{array}{l}\text { Describe sources of funding for the systematic review and other support (eg, } \\
\text { supply of data); role of funders for the systematic review. }\end{array}$ & 15 \\
\hline
\end{tabular}

TABLE E3. Quality assessment tool for observational cohort or randomized controlled intervention studies

\begin{tabular}{lll}
\hline \multicolumn{1}{c}{ Author } & Year & Quality rating \\
\hline Byhahn & 2000 & Poor \\
Curtis & 2001 & Poor \\
Force & 2005 & Fair \\
Walts & 2006 & Poor \\
Rahmanian & 2007 & Fair \\
Yavas & 2008 & Fair \\
Gaudino & 2009 & Fair \\
Ballotta & 2011 & Good \\
Trouillet & 2011 & Good \\
Devarajan & 2012 & Good \\
Sun & 2013 & Good \\
Ben-Avi & 2014 & Fair \\
Hosseinian & 2014 & Fair \\
\hline
\end{tabular}

TABLE E4. Reasons for study exclusion

\begin{tabular}{ll}
\hline \multicolumn{1}{c}{ Author, $\mathbf{y}$} & \multicolumn{1}{c}{ Reason for exclusion } \\
\hline Balasubramaniam MS, 2010 & Abstract/conference \\
Bryan CS, 2013 & Review \\
Dimarakis I, 2010 & Abstract/conference \\
Gelape CL, 2007 & Review \\
Gulmen S, 2009 & Abstract/conference \\
Kubota H, 2013 & Review \\
Kusachi S, 2009 & Abstract/conference \\
Lehr EJ, 2011 & Case report \\
Marulli G, 2012 & Abstract/conference \\
Mitrev Z, 2011 & Abstract/conference \\
Okonta KE, 2011 & Review \\
Pilarczyk K, 2014 & Abstract/conference \\
Reyna GC, 2006 & Review \\
Sachithanandan A, 2008 & Tracheostomy-specific outcomes \\
& not reported \\
Singh K, 2011 & Review \\
Stamenkovic SA, 2000 & SWI outcome not reported \\
Vollroth M, 2011 & Abstract/conference \\
Wasowicz M, 2009 & Abstract/conference \\
Wagner F, 1998 & SWI outcome not reported \\
\hline SWI Sternal wound infection &
\end{tabular}

